\title{
Revisão do gênero Kroeberia Lindner (Diptera, Ropalomeridae) da Região Neotropical
}

\author{
Ana Paula Coelho Marques ${ }^{1} \&$ Rosaly Ale-Rocha ${ }^{2}$
}

\begin{abstract}
'Pós-Graduação em Entomologia, Departamento de Zoologia, Universidade Federal do Paraná-UFPR. Caixa Postal 19020, 81531-980 Curitiba-PR, Brasil. Endereço eletrônico: apcm@ufpr.br

${ }^{2}$ Coordenação de Pesquisas em Entomologia, Instituto Nacional de Pesquisas da Amazônia-INPA. Caixa Postal 478, 69011-970 ManausAM, Brasil. Endereço eletrônico: alerocha@inpa.gov.br.
\end{abstract}

\begin{abstract}
Aвstract. Revision of the genus Kroeberia Lindner (Diptera, Ropalomeridae) of the Neotropical Region. The genus Kroeberia Lindner, 1930 and the species K. fuliginosa Lindner, 1930, are redescribed. A new species, K. minor, is described from Brazil (Pará and Amazonas). The two species are illustrated and keyed.

Keywords. Distribution; identification key; Kroeberia; new species; taxonomy.

Resumo. O gênero Kroeberia e a espécie K. fuliginosa Lindner, 1930, são redescritos. Uma espécie nova, K. minor, é descrita do Brasil (Pará e Amazonas). As duas espécies são ilustradas e uma chave de identificação é fornecida.

Palavras-chave. Distribuição; chave de identificação; espécie nova; Kroeberia; taxonomia.
\end{abstract}

A família Ropalomeridae compreende, atualmente, 26 espécies válidas distribuídas em oito gêneros (STEYSKAL 1967; RAMírEZ-GARCía \& HERNÁNDEZ-ORTIZ 1994). É principalmente neotropical, ocorrendo desde o Sul dos Estados Unidos da América até o Norte da Argentina, com uma única espécie conhecida na Região Neártica, Rhytidops floridensis (Aldrich, 1932) (STEYSKAL 1987). No Brasil foram registradas 21 espécies em seis gêneros (Steyskal 1967; Prado \& Papavero 2002).

Kroeberia Lindner, 1930 é um gênero de moscas castanhas, de tamanho médio, com fronte pouco côncava, face com tubérculo central arredondado, arista nua ou com pêlos microscópicos, escutelo cerdoso e pernas com os fêmures bastante engrossados. O gênero é monotípico, incluindo apenas a espécie-tipo Kroeberia fuliginosa Lindner, 1930, descrita de exemplar do Rio Grande do Sul, Brasil, e também registrada nos estados do Mato Grosso, Rio de Janeiro, São Paulo, Amapá, Amazonas, Acre e Roraima (FISCHER 1932; PRADO 1966; Ale-Rocha \& Marques, no prelo). Ocorre também no México, Panamá e Venezuela (Steyskal 1967; Baez 1985).

Neste trabalho uma nova espécie é descrita, Kroeberia minor sp. nov. e K. fuliginosa é registrada pela primeira vez no Estado de Goiás, Brasil.

\section{MATERIAL E MÉTODOS}

Para este estudo, foram examinados 67 espécimes montados em alfinetes: 48 exemplares de K. fuliginosa e 19 de K. minor sp. nov.

O abdome foi desprendido para análise das estruturas da terminália. A terminália masculina foi aquecida em ácido láctico $85 \%$, por 15-30 minutos em média. A terminália feminina, por ser mais frágil, permaneceu em solução de hidróxido de potássio $10 \%$ a frio durante cerca de $24-48$ horas.
Posteriormente, foi colocada em solução de ácido acético e lavada em água destilada. As peças foram acondicionadas em microtubos de plástico $(4 \times 10 \mathrm{~mm})$, com glicerina, e afixados no alfinete do espécime.

A asa foi destacada e mergulhada em xilol por algumas horas sendo, posteriormente, montada com bálsamo do Canadá, entre lamínulas e fotografada.

A terminologia empregada segue o trabalho de MCALPINE (1981).

As abreviaturas citadas no texto correspondem às seguintes instituições: INPA, Instituto Nacional de Pesquisas da Amazônia, Manaus; MPEG, Museu Paraense Emílio Goeldi, Belém; MZSP, Museu de Zoologia, Universidade de São Paulo, São Paulo; NHMW, Naturhistorisches Museum Wien, Viena; USNM, National Museum of Natural History, Washington.

\section{Kroeberia Lindner, 1930}

Kroeberia Lindner, 1930: 125 (chave, descrição); Aldrich, 1932: 9 (redescrição); Malloch, 1941: 50 (diagnose); Prado, 1966: 213 (chave, diagnose); Steyskal, 1967: 1 (catálago); Ramírez-García \& Hernández-Ortiz, 1994: 75 (diagnose); Prado \& Papavero, 2002: 1 (catálogo).

Espécie-tipo: Kroeberia fuliginosa Lindner, 1930 (designação original).

Diagnose. Espécies de tamanho médio, 9,7-12,5 mm; fronte pouco côncava; face com tubérculo central arredondado; arista nua ou com pêlos microscópicos; cerdas orbitais ausentes; ocelares, pós-ocelares, vertical interna e externa presentes; escutelo cerdoso, com cerdas espiniformes no disco; 5-7 cerdas na borda superior do espiráculo metatorácico; pernas com os fêmures bastante engrossados.

Descrição (macho e fêmea). Cabeça: trapezoidal; fronte 
ampla, com duas manchas pequenas irregulares de polinosidade prateada situadas anteriormente à região ocelar; cerdas ocelar, pós-ocelar, verticais interna e externa presentes; tubérculo facial arredondado; órbitas oculares com faixa muito estreita de polinosidade prateada na região inferior, alargandose próximo à base das antenas; escapo e pedicelo com várias cerdas, pedicelo com 1-2 cerdas maiores na margem dorsal; flagelo sem cerdas, com polinosidade dourada esparsa nas faces externa e interna; arista nua ou com pilosidade microscópica; gena ampla, cerdosa, com faixa longitudinal de polinosidade dourada; pós-gena com várias cerdas.

Tórax: escuto com faixas de polinosidade prateada, cerdas de revestimento curtas, e várias cerdas destacadas. Escutelo com o dorso convexo e várias cerdas curtas na região discal (Figs. 1, 10). Subescutelo com polinosidade prateada. Faixa de polinosidade prateada estendendo-se da propleura até o metepimero; anepisterno com 1-3 cerdas destacadas, cercadas por cerdas mais fracas; catepisterno com 1 cerda destacada; 5-7 cerdas na borda superior do espiráculo metatorácico.

Asas: semi-hialinas com ou sem tonalidade amarelada uniformemente distribuída, sem manchas distintas; $\mathrm{R}_{4+5}$ quase reta, levemente côncava próxima ao ápice; forquilha do Setor Radial e final da Sc separados por uma distância equivalente ao comprimento do Setor Radial; última seção da $M$ quase reta, levemente convexa na metade basal; $\mathrm{CuA}_{2}$ levemente arqueada (Figs. 27, 28).

Pernas: fêmures engrossados, com uma cerda fina e longa na base da face ventral, com polinosidade prateada esparsamente distribuída nas faces anterior e dorsal, mais acentuada no fêmur posterior; tíbias anterior e média com 1 cerda subapical dorsal distintamente diferenciada; tíbia média com 3 cerdas fortes apicais ventrais; tíbia posterior mais alargada, achatada lateralmente, com a face dorsal laminar e 68 cerdas longas, e destacadas na margem póstero-dorsal (Figs. $2,11)$.

Abdome: tergitos 2-5 cobertos por fina polinosidade, esparsamente distribuída. Terminália feminina telescopada, membranosa na maior parte; segmento 7 parcialmente membranoso, tergito 7 representado por uma placa nos $2 / 3$ basais, com um par de cerdas na porção basal (Figs. 19, 23); esternito 7 reduzido a uma pequena placa basal com um par de cerdas (Figs. 20, 24); um espiráculo nos segmentos 6 e 7; hipoprocto cerdoso, com uma fenda mediana longitudinal que não atinge o ápice (Figs. 20, 24); cerco cerdoso, com cerdas maiores no ápice. Terminália masculina: cercos bastante cerdosos, longos e finos, fusionados somente na base e providos de longas cerdas no ápice (Figs. 4-5, 13-14); edeago cilíndrico, membranoso na porção apical (Figs. 7-8, 16-17); epifalo curto e quase reto; parâmero bilobado, com os lóbulos diferenciados (Figs. 7-9, 16-18).

Distribuição geográfica. México, Panamá, Venezuela e Brasil.

Comentários. Difere dos demais gêneros por ter cerdas ocelares, pós-ocelares, verticais interna e externa presentes; escutelo cerdoso, com cerdas espiniformes no disco; 5-7 cerdas na borda superior do espiráculo metatorácico. As espécies dessse gênero podem ser separadas por caracteres morfológicos externos, e, principalmente, pela morfologia das terminálias masculina e feminina.

\section{Chave para as espécies de Kroeberia (macho e fêmea)}

1. Arista nua; escutelo com 2 cerdas discais destacadas, sendo 1 mediana e 1 no terço basal (Fig. 1); esternito 5 do macho aproximadamente quadrado, com 5 cerdas detacadas no ângulo póstero-lateral (Fig. 3); surstilo fortemente esclerotinizado, margens interna e apical com projeções dentiformes (Figs. 4-6); epifalo alongado e afilado, com extremidade apical levemente pontiaguda (Figs. 7-8); parâmero com lóbulo apical interno levemente pontiagudo (Figs. 8-9); espermateca alongada com finas estriações transversais (Fig. 22) ...

K. fuliginosa Lindner

Arista com pêlos microscópicos; escutelo com 1 cerda subapical e 1 discal no terço distal (Fig. 10); esternito 5 do macho retangular, com uma fileira de 5-6 cerdas laterais, a posterior mais longa (Fig. 12); surstilo fracamente esclerotinizado, margem interna lisa e 1-3 projeções dentiformes na margem apical, base com projeção lateral arredondada (Figs. 13-15); epifalo curto e engrossado, com a extremidade apical arredondada (Figs. 16-17); parâmero com lóbulo interno truncado (Figs. 16-18); espermateca arredondada sem estriações transversais (Fig. 26) K. minor sp. nov.

Kroeberia fuliginosa Lindner, 1930

(Figs. 1-9, 19-22, 27)

Kroeberia fuliginosa Lindner, 1930: 127; Aldrich, 1932: 9 (redescrição); Fischer, 1932: 450 (diagnose); Prado, 1966: 253 (redescrição, distr. geográfica); Steyskal, 1967: 1 (catálogo); Baez, 1985: 79 (distr. geográfica); Ramírez-García \& Hernández-Ortiz, 1994: 76 (redescrição, distr. geográfica, chave); Prado \& Papavero, 2002: 1 (catálogo).

Diagnose. Arista nua; escutelo com 1 cerda apical e 2 discais (1 mediana e 1 no terço basal); terminália feminina: espermateca alongada com finas estriações transversais. Esternito 5 do macho quase quadrado, com 5 cerdas destacadas no ângulo póstero-lateral; terminália masculina: surstilo fortemente esclerotinizado, margens interna e apical com projeções dentiformes; epifalo alongado e afilado com extremidade apical levemente pontiaguda; parâmero com lóbulo apical interno levemente pontiagudo.

Holótipo macho. Corpo: 9,8 mm; asa: 8,7 mm x 3,2 mm.

Cabeça: fronte castanho-escura; face amarelada; esclerito parafacial amarelo com cerdas castanhas; antena alaranjada; pedicelo com 2 cerdas maiores na margem dorsal; arista nua, com a base amarelada, o restante castanho; clípeo alaranjado; palpo castanho; gena e pós-gena amareladas com cerdas ruivas. 

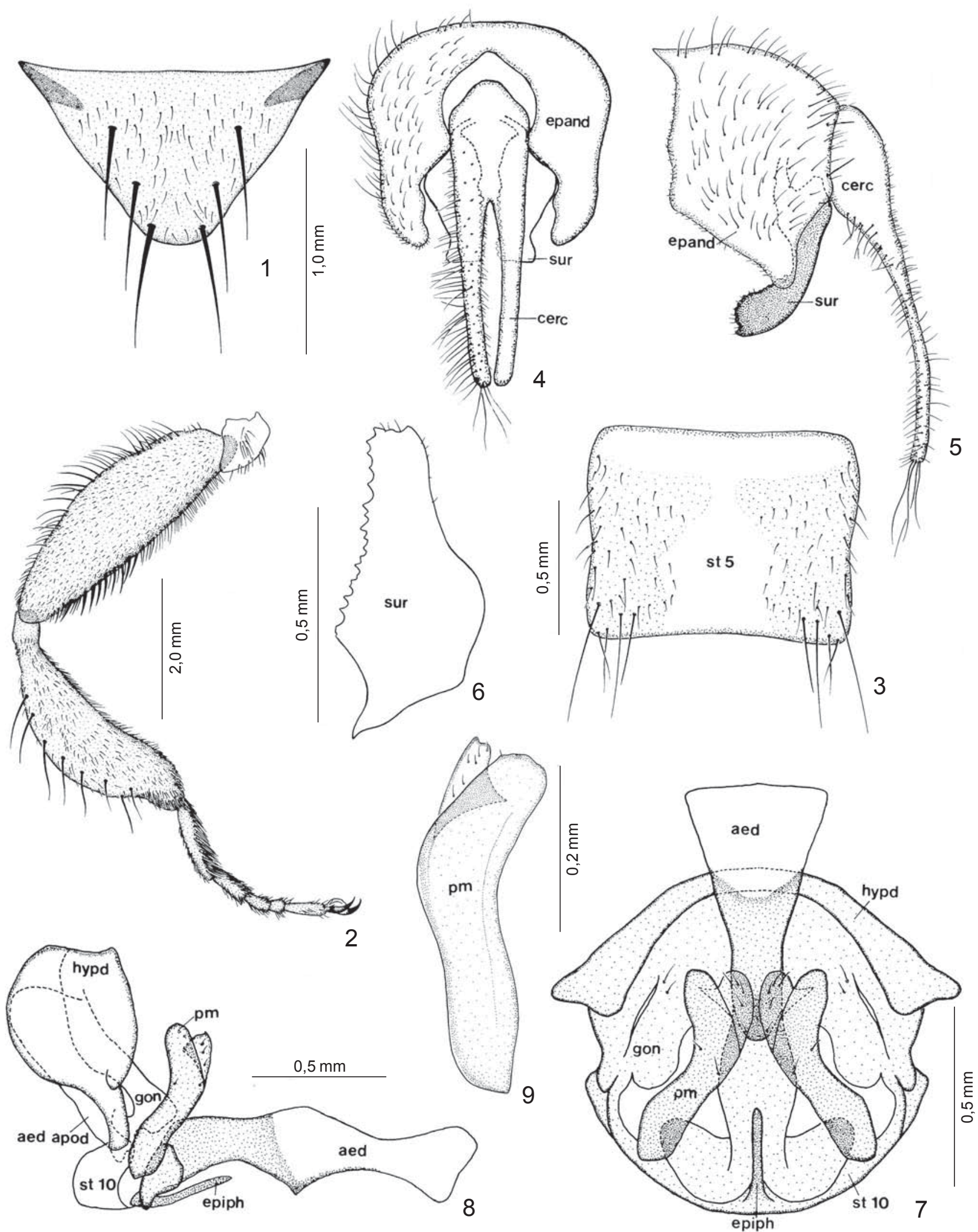

Figs. 1-9. Kroeberia fuliginosa Lindner (macho): 1, escutelo (vista dorsal); 2, perna posterior esquerda; 3, esternito 5 (vista ventral); 4-5, terminália masculina (vistas ventral e lateral, mesma escala); 6, surstilo esquerdo (vista lateral); 7-8, terminália masculina (vistas ventral e lateral); 9, parâmero esquerdo; aed = edeago; aed apod = apódema do edeago; cerc = cerco; epand = epândrio; epiph = epifalo; gon = gonópodo; hypd = hipândrio; pm = parâmero; st = esternito; sur = surstilo. 
Tórax: escuto castanho-escuro, com as seguintes faixas de polinosidade prateada: 1 acrostical estreita, 1 dorsocentral e 1 lateral mais largas, esta última estendendo-se do lóbulo pós-pronotal até o calo pós-alar; cerdas de revestimento curtas e pretas; cerdas destacadas: 2 pós-pronotais (a mais interna menor), 2 notopleurais, 1 supra-alar pré-sutural, 1 supraalar pós-sutural, 1 pós-alar, 2 intra-alares (a anterior mais reduzida), 1 intra-pós-alar, 2 dorsocentrais pré-escutelares póssuturais e 1 acrostical pré-escutelar pós-sutural. Escutelo castanho-escuro, base com duas pequenas manchas de polinosidade prateada nas laterais; 1 cerda apical, 2 discais ( 1 mediana e 1 no terço basal) e várias cerdas menores pretas na região discal. Propleura, anepisterno e anepimero castanhos e sem brilho; anepisterno com 2-3 cerdas robustas cercadas por cerdas mais fracas; catepisterno alaranjado com 1 cerda destacada; um tufo de 6 cerdas desenvolvidas no anepimero e numerosas cerdas mais finas; 7 cerdas na borda superior do espiráculo metatorácico.

Asas: tégula com 4 cerdas destacadas; semi-hialinas com tonalidade amarelada uniformemente distribuída, sem manchas distintas; medidas das seções da veia Costa: I 1.5 mm, II 2.7 $\mathrm{mm}$, III $2 \mathrm{~mm}$, IV $1.5 \mathrm{~mm}, \mathrm{~V} 0.5 \mathrm{~mm}$ e VI $0.3 \mathrm{~mm}$.

Pernas: coxas e trocanteres alaranjados; coxa anterior com polinosidade prateada e cerdas ruivas; fêmures engrossados, alaranjados na base, o restante castanho-escuro. Fêmur anterior: com inúmeras cerdas dorsais longas distribuídas irregularmente; face ventral com uma fileira de 9 cerdas diferenciadas na metade apical da margem anterior, cercadas por cerdas mais longas e finas, margem posterior com 8 cerdas curtas na metade apical. Fêmur médio: face dorsal com várias cerdas distribuídas irregularmente na margem anterior; face ventral com uma fileira de 16 cerdas curtas na margem anterior e 14 cerdas curtas na margem posterior. Fêmur posterior (Fig. 2): numerosas cerdas dorsais sem formar série definida e várias cerdas ventrais curtas aleatoriamente distribuídas. Tíbias castanho-escuras, face anterior da tíbia posterior com polinosidade prateada. Tarsos anterior e médio com os tarsômeros 1 e 2 amarelados, os demais castanhos. Tarso posterior castanho.

Abdome: castanho-escuro, com os tergitos 2-5 cobertos por fina polinosidade, podendo haver reflexos metálicos em tons azul, verde, rosa ou amarelo; esternito 5 do macho aproximadamente quadrado, com 5 cerdas longas no ângulo póstero-lateral, cercadas por cerdas menores (Fig. 3); surstilo fortemente esclerotinizado, com as margens interna e apical providas de projeções dentiformes (Figs. 4-6); epifalo alongado e afilado, com o ápice levemente pontiagudo (Figs. 7-8); parâmero com o lóbulo apical externo arredondado, o interno levemente pontiagudo (Figs. 7-9).

\section{Fêmea. Corpo: 12,5 mm; asa: $9 \mathrm{~mm}$ x $3.5 \mathrm{~mm}$.}

Asas (Fig. 27) como no macho exceto pelo que segue: medidas das seções da veia Costa: I $1.7 \mathrm{~mm}$, II $3 \mathrm{~mm}$, III $2 \mathrm{~mm}$, IV $1.5 \mathrm{~mm}, \mathrm{~V} 1 \mathrm{~mm}$ e VI $0.5 \mathrm{~mm}$. Pequenas cerdas presentes na margem distal e 1 par de cerdas delgadas próximo da base do tergito 7 (Fig. 19); cerdas maiores na porção membranosa do segmento 7 (Fig. 20); espermateca alongada com finas estriações transversais (Fig. 22); epiprocto com 1 par de cerdas destacadas na porção apical (Figs. 19 e 21).

Distribuição geográfica. México, Panamá, Venezuela, Brasil (Acre, Amapá, Roraima, Amazonas, Mato Grosso, Goiás, Rio de Janeiro, São Paulo e Rio Grande do Sul).

Material-tipo examinado. Holótipo macho (NHMW), etiquetado: "[BRASIL], Stieglmayr, Rio Gr[ande] do Sul, [sem data]", "Ropalom. do gen. a/ det. Hendel", "Kröeberia fuliginosa macho Lind.", "Type Lindner 1928" (etiqueta branca). Parátipos: ibidem, 1 macho (NHMW), etiquetado: "Cotype Lindner 1928" (etiqueta branca); 1 fêmea (NHMW), etiquetado: "Brasilien, [sem data]", "femoratis/ Alte Sammlung", "Kroeberia fuliginosa fêmea Lind.", "Cotype Lindner 1928" (etiqueta vermelha).

Condição do holótipo. Coberto com hifas secas; perna anterior direita montada em triângulo de papel preso no mesmo alfinete do espécime; abdome não dissecado; montagem não permitindo a visualização de várias cerdas das pernas (as estruturas muito danificadas ou pouco visíveis foram descritas a partir de outros espécimes machos, comparados com o holótipo).

Material examinado. MÉXICO. Jalisco, Est. Biol. Chamela, 22.VII.1988, E. Ramírez leg., 1 macho (USNM); ibidem, 7.IX.1989, 1 fêmea (USNM); [Oaxaca], Tehuantepec, [sem data, sem cabeça], 1 macho (USNM); [PANAMÁ], [Panamá], [Parque Nacional] Campana, X-XI.1937, "fruit fly trap", $n^{\circ} 4075$, lote $n^{\circ}$ 38-16492, J. Zetek leg., 1 fêmea (USNM). BRASIL. Roraima, Ilha de Maracá, 20-30.III.1987, arm[adilha] Malaise, Luis S. Aquino leg., 1 macho (INPA); Amazonas, Embrapa, AM-010 km 31, 12.XII.1991, arm[adilha] Shannon, isca de fruta, capoeira, L. P. Albuquerque \& J. Bindá leg., 2 fêmeas (INPA); ibidem, 19.II.1992, 1 fêmea (INPA); ibidem, 12.XII.1991, C[ultura de] andiroba, 2 fêmeas e 1 macho (INPA); ibidem, 6.XI.1991, C[ultura de] cacau, 2 fêmeas (INPA); ibidem, 6.II.1992, 1 fêmea (INPA); ibidem, 15.I.1992, C[ultura de] guaraná, 1 fêmea (INPA); R[eserva] Adolpho Ducke [AM $010 \mathrm{~km} \mathrm{26],9-16.X.2002,} \mathrm{arm[adilha]} \mathrm{McPhail,} \mathrm{área}$ aberta, baixio, E. F. Soares \& A. L. Pinheiro leg., 1 fêmea e 1 macho (INPA); ibidem, 16.X.2002, platô, 1 fêmea (INPA); ibidem, 2 9.X.2002, mata, platô, 1 macho (INPA); ibidem, 24.XI-01.XII.1988, isca de fruta, Y. Camara \& J. F. Vidal leg., 1 fêmea (INPA); ibidem, 16.III-06.iv.1989, 2 machos (INPA); ibidem, 12-19.I.1989, Y. Camara \& J. E. Binda leg., 2 fêmeas (INPA); ibidem, 27.IV-09.V.1989, 1 fêmea (INPA); ibidem, 10-15.VI.1989, 1 fêmea (INPA); ibidem, 10 17.VIII.1989, isca de fruta, $20 \mathrm{~m}, 1$ macho (INPA); ibidem, 2428.VI.1988, isca de fruta, Y. Camara \& F. Xavier leg., 1 macho (INPA); ibidem, 16.VI.2003, arm[adilha] McPhail modificada, $15 \mathrm{~m}, \mathrm{~A} . \mathrm{P}$. Tregue-Costa leg., 3 fêmeas (INPA); E[scola] A[grícola] R[ainha dos] A[póstolos], BR-174 km 23, 13.II.1997, arm[adilha] McPhail, em abiu, B. Ronchi-Teles leg., 1 fêmea (INPA); ibidem, 20.II.1997, em abiu, 1 macho (INPA); E[stação] E[xperimental de] F[ruticultura] T[ropical], BR-174 km 40, 22.V.1997, arm[adilha] McPhail, em araticum, B. Ronchi-Teles leg., 1 fêmea (INPA); ibidem, em ingá, 1 macho (INPA); ibidem, 28.V.1997, em goiaba, 1 macho (INPA); CEPLAC, IV.2001, arm[adilha] McPhail, B. Ronchi-Teles leg., 1 fêmea (INPA); Acre, Cruzeiro do Sul, Rio Moa, 07³7'02"S 7246'15"W, 19 28.XI.1996, arm[adilha] Malaise, 1 fêmea (INPA); Mato Grosso, Maracajú, VII.1937, Serviço Febre Amarela, M.E.S., Bras., 1 fêmea (USNM); Mun[ícipio] Três Lagoas, F[azenda] Floresta, 13-20.IX.1964, Exp. Dpto. Zool., “Shannon's traps”, 1 macho (MZSP); Goiás, Corumbá, F[azenda] Monjolinho, [sem data], Barretto leg., 2 machos (MZSP); Rio de Janeiro, X.1938, "Yel[low] Fev[er] Serv[ice]" [= Serviço Febre Amarela], M.E.S. Brazil, RC Shannon, 2 fêmeas (USNM); São Paulo, Anhembi, Faz[enda] B. Rico, 14.II.1969, W. Kempf, J. C. Magalhães, L. T. F. \& N. Kuhlmann leg., Ric. Trav. [?], 1 fêmea (MZSP).

Variações. Coloração da face variável, podendo ser amarela, castanha ou preta; coloração da antena com tons amarelados 

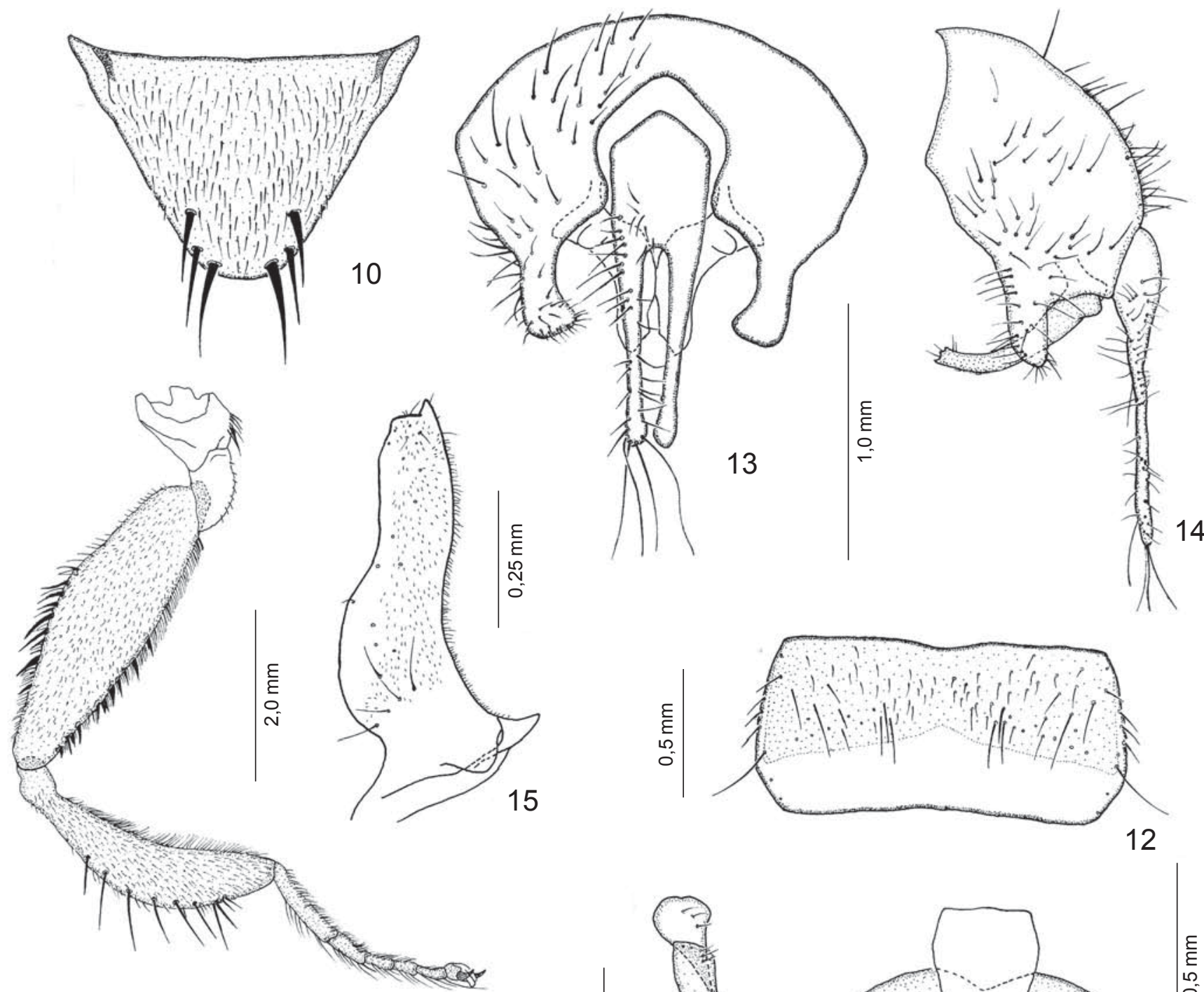

15

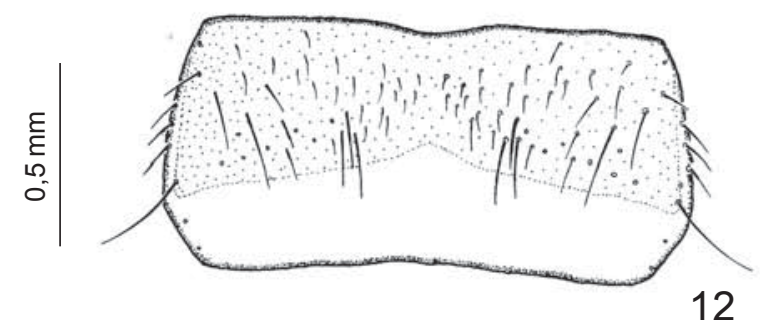

12
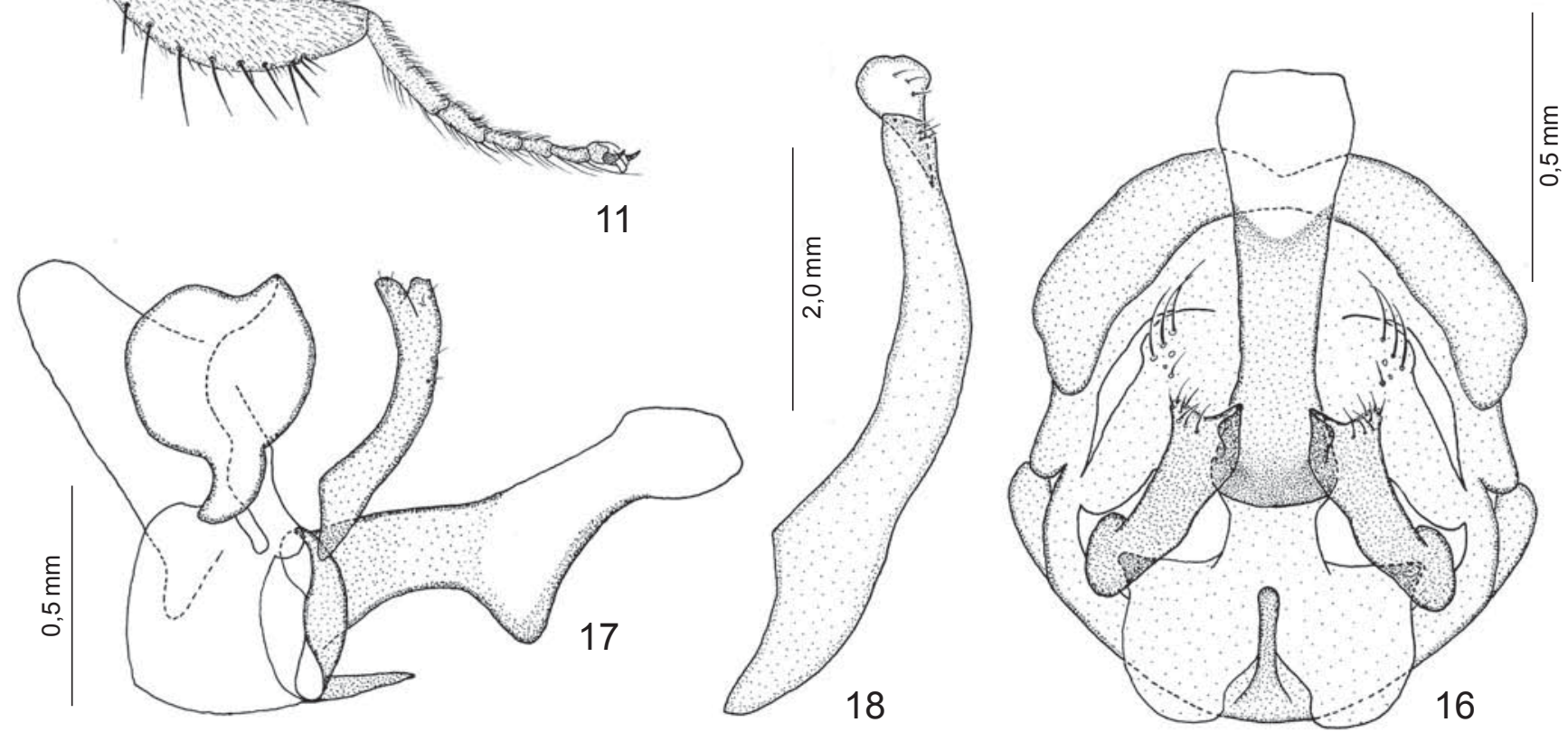

Figs. 10-18. Kroeberia minor sp. nov. (parátipo macho): 10, escutelo (vista dorsal); 11, perna posterior esquerda; 12, esternito 5 (vista ventral); 13-14, terminália masculina (vistas ventral e lateral, mesma escala); 15, surstilo esquerdo (vista lateral); 16-17, terminália masculina (vistas ventral e lateral); 18, parâmero esquerdo. 

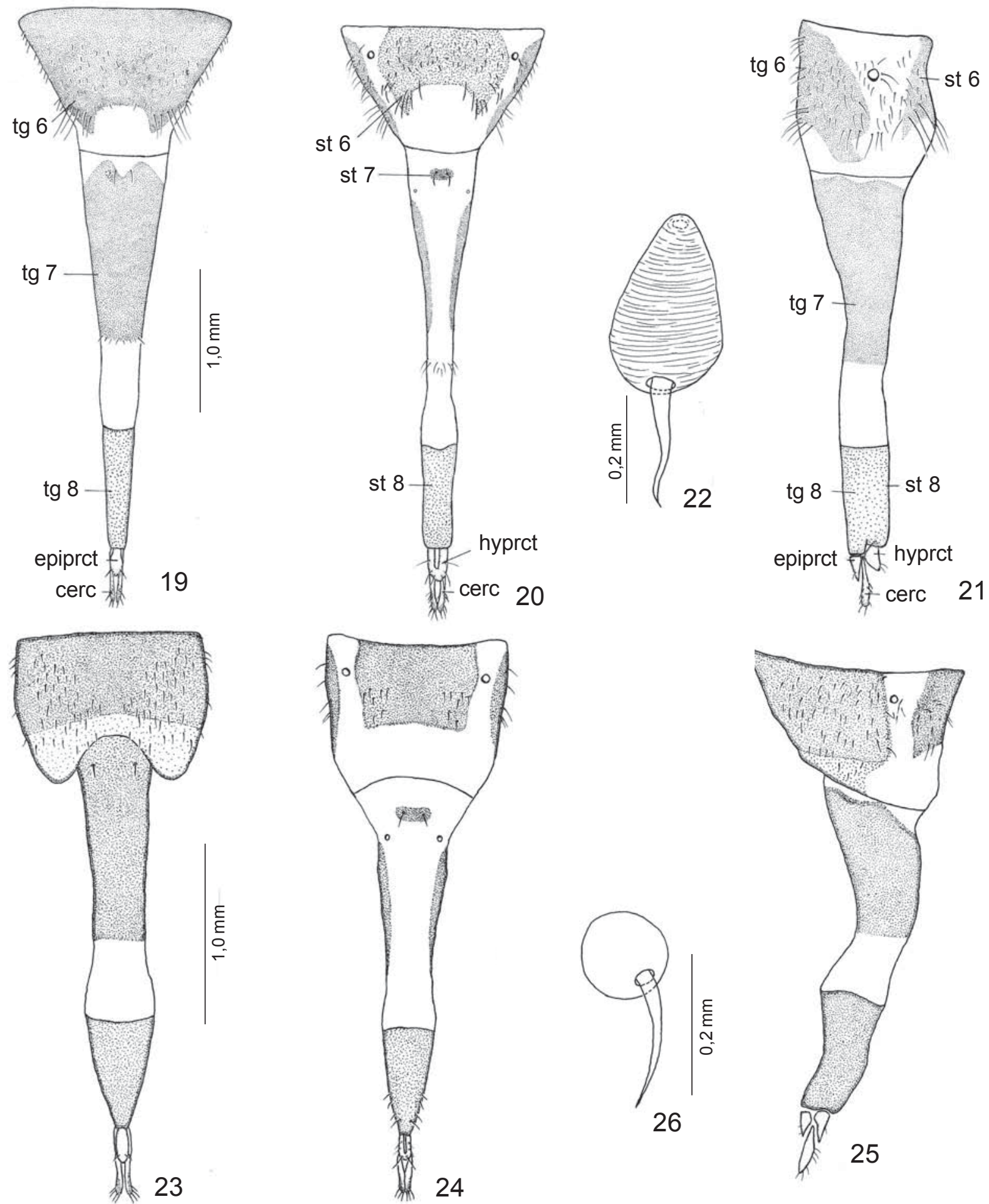

Figs. 19-26. Terminália feminina (vistas dorsal, ventral e lateral) e espermateca: 19-22, K. fuliginosa (fêmea); 23-26, K. minor (parátipo); cerc $=$ cerco; epiprct $=$ epiprocto; hyprct $=$ hipoprocto; $s t=$ esternito; $\operatorname{tg}=$ tergito.

ou castanhos; clípeo, palpo e gena seguindo o padrão de coloração da face; esclerito parafacial com muitas cerdas ruivas, em algumas fêmeas; gena e pós-gena com cerdas ruivas e/ou pretas; escutelo com 1 cerda apical e 3 discais; catepisterno castanho a castanho-escuro; 5-7 cerdas na borda superior do espiráculo metatorácico; tégula com 3-5 cerdas destacadas; número de cerdas dos fêmures bastante variável, mas sempre com o mesmo padrão de distribuição.

Comentários. K. fuliginosa assemelha-se a K.minor sp. nov. 
no aspecto geral, sendo, entretanto, um pouco maior que esta última. Difere de $K$. minor sp. nov., principalmente, pela arista totalmente nua; pela disposição das cerdas escutelares; pelo formato da espermateca, alongada e com estriações transversais; e pelo aspecto geral da terminália masculina, principalmente o surstilo que é muito esclerotinizado e com margens denteadas, o epifalo afilado com o ápice levemente pontigudo e o parâmero com o lóbulo apical externo arredondado e o interno levemente pontiagudo.

\section{Kroeberia minor sp. nov.}

(Figs. 10-18, 23-26 e 28)

Diagnose. Arista com pêlos microscópicos; escutelo com 1 cerda apical, 1 subapical e 1 discal no terço distal; terminália feminina: espermateca arredondada, sem estriações transversais. Esternito 5 do macho retangular, com uma fileira de 5-6 cerdas laterais, a posterior mais longa; terminália masculina: surstilo fracamente esclerotinizado, margem interna lisa e 1-3 projeções dentiformes na margem apical, base com projeção lateral arredondada; epifalo curto e engrossado, com a extremidade apical arredondada; parâmero com lóbulo apical externo arredondado e o interno truncado.

Holótipo macho. Corpo: 9,7 mm; asa: 7,6 mm x 2,6 mm.

Cabeça: fronte castanho-escura; face amarelada; esclerito parafacial amarelo com cerdas castanhas; antena alaranjada; pedicelo com 1 cerda maior na margem dorsal; arista com pêlos microscópicos, a base amarelada, o restante castanho; clípeo amarelado; palpo alaranjado; gena e pós-gena amareladas com cerdas ruivas.

Tórax: escuto castanho-escuro, com as seguintes faixas de polinosidade prateada: 1 dorsocentral e 1 lateral mais larga, que se estende do lóbulo pós-pronotal até o calo pós-alar; cerdas de revestimento curtas e pretas; cerdas destacadas: 1 pós-pronotal; 2 notopleurais; 1 supra-alar pré-sutural; 1 pósalar; 1 intra-alar; 1 intra-pós-alar; 1 dorsocentral pré-escutelar reduzida e fraca e 1 acrostical pré-escutelar pós-sutural. Escutelo castanho-escuro, com 1 cerda apical, 1 subapical marginal, 1 discal no terço distal e várias cerdas menores pretas na região discal. Propleura, anepisterno e anepimero castanhos e sem brilho; anepisterno com 1 cerda robusta cercada por cerdas mais fracas; catepisterno castanho com 1 cerda destacada; anepimero com numerosas cerdas fracas aleatoriamente distribuídas; 7 cerdas na borda superior do espiráculo metatorácico.

Asas (Fig. 28): tégula com 6 cerdas destacadas; semihialinas sem tonalidade amarelada uniformemente distribuída ou manchas distintas; medidas das seções da veia Costa: I 1.5 mm, II $2.3 \mathrm{~mm}$, III $1.7 \mathrm{~mm}$, IV $1.5 \mathrm{~mm}$, V 1mm, VI $0.3 \mathrm{~mm}$.

Pernas: coxas com polinosidade prateada e cerdas ruivas; trocanteres alaranjados a castanhos; fêmures engrossados; fêmures anterior e médio com os $2 / 3$ basais alaranjados, 0 restante castanho-escuro; fêmur posterior castanho-escuro, alaranjado somente na face dorsal. Fêmur anterior: com inúmeras cerdas dorsais longas distribuídas irregularmente;
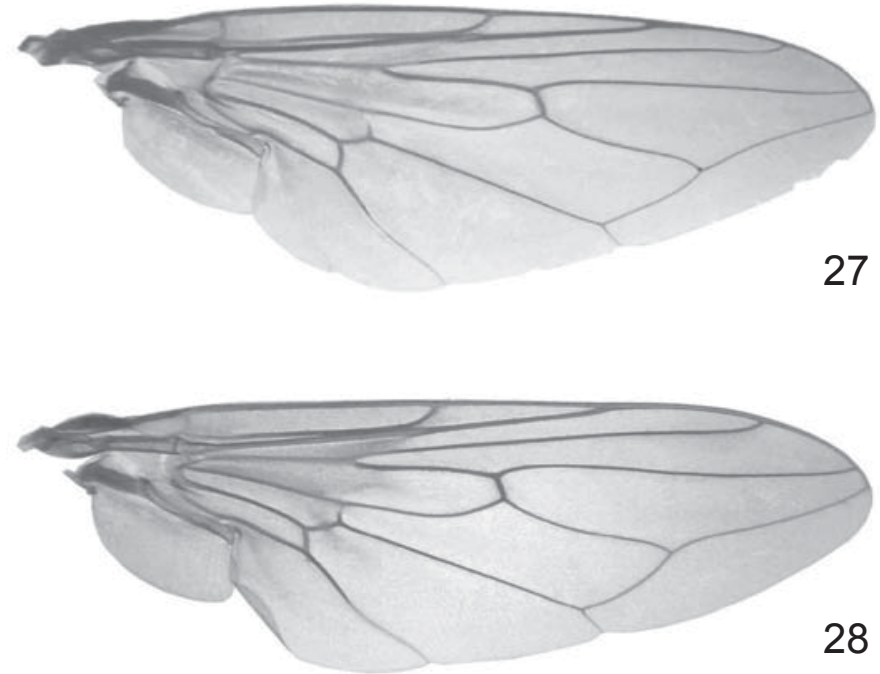

Figs. 27-28. Asas: 27, K. fuliginosa (fêmea); 28, K. minor (parátipo macho).

face ventral com duas fileiras irregulares de aproximadamente 20 cerdas curtas na metade apical da margem anterior, margem posterior com uma fileira de 9-10 cerdas curtas. Fêmur médio: face dorsal com várias cerdas distribuídas irregularmente na margem anterior; face ventral com uma fileira de 15 cerdas curtas na margem anterior e uma de 8 cerdas na margem posterior. Fêmur posterior (Fig. 11): face dorsal com numerosas cerdas sem formar série definida; face ventral com uma fileira de 8-10 cerdas curtas no terço apical da margem anterior e cerca de 6 cerdas na margem posterior. Tíbia anterior: face anterior castanho-escura, face posterior alaranjada com várias cerdas ruivas; tíbia média castanho-escura; tíbia posterior com intensa pilosidade ventral. Tarsos anterior e médio alaranjados com cerdas pretas dorsalmente e ruivas ventralmente; tarsômero 1 do tarso posterior com intensa pilosidade ventral de reflexos dourados.

Abdome: castanho-escuro, com os tergitos 2-5 cobertos por fina polinosidade esparsa prateada; esternito 5 do macho retangular, 2,5 vezes mais largo que longo, com uma fileira de 5-6 cerdas laterais, a cerda posterior mais longa (Fig. 12); surstilo fracamente esclerotinizado, com a margem interna lisa e 1-3 projeções dentiformes na margem apical, base com projeção lateral arredondada (Figs. 13-15); epifalo curto e engrossado, com a extremidade apical arredondada (Figs. 1617); parâmero com o lóbulo apical externo arredondado e o interno truncado (Figs. 16-18).

Fêmea. Corpo: 10,5 mm; asa: 7,8 mm x 2,5 mm.

Como no macho, exceto pelo que segue: medidas das seções da veia Costa: I $1.5 \mathrm{~mm}$, II $2 \mathrm{~mm}$, III $1.6 \mathrm{~mm}$, IV $1.7 \mathrm{~mm}$, V $1 \mathrm{~mm}$, VI $0.3 \mathrm{~mm}$. Coxas cobertas por polinosidade prateada e com cerdas pretas e ruivas, menores que no macho; tíbias castanho-escuras; terminália mais curta que em $K$. fuliginosa; espermateca arredondada, sem estriações transversais (Fig. 
26); tergito 7 com 1 par de cerdas próximo da base (Fig. 23); epiprocto com 1 par de cerdas na porção apical (Figs. 23 e 25).

Distribuição geográfica: Brasil (Pará e Amazonas).

Holótipo macho (INPA), etiquetado: BRASIL, Amazonas, [Manaus], R[eserva Adolpho] Ducke [AM-010, Km 26, 2053'S $\left.59^{\circ} 59^{\prime} \mathrm{W}\right], 16 . I V .1992$, armadilha de óleo, 1-20m, mata, J. Vidal leg. (etiqueta impressa branca)/ Holótipo, Kroeberia minor, Marques \& Ale-Rocha (etiqueta impressa vermelha). Condição do holótipo: em perfeito estado de conservação, não dissecado.

Parátipos: BRASIL. Pará, Serra Norte, Salobo, 11-14.VIII.1984, [coletor anônimo], arm[adilha] suspensa, $20 \mathrm{~m}, 1$ macho (MPEG); Amazonas, Embrapa AM-010 km 31, 10.IX.1990, arm[adilha] Shannon, C[ultivo de] andiroba, isca de fruta, L. P. Albuquerque \& J. E. Binda leg., 1 macho (INPA); R[eserva] [Adolpho] Ducke [AM $010 \mathrm{~km}$ 26], 01-07.XII.1988, isca de fruta, Y. Camara \& J. F. Vidal leg., 1 macho (INPA); ibidem, 22-29.XII.1988, 2 fêmeas (INPA); ibidem, 19-26.VIII.1988, isca de fruta, Y. Camara \& F. Xavier leg., 1 fêmea (INPA); ibidem, 01-08.IX.1988, isca de fruta, Y. Camara \& J. E. Binda leg., 1 fêmea (INPA); ibidem, 06-12.I.1989, 1 fêmea (INPA); 0620.X.1994, arm[adilha] suspensa, torre, 30m, J. A. Rafael \& J. Vidal leg., 1 fêmea (INPA); ibidem, 9-16.X.2002, arm[adilha] McPhail, área aberta, baixio, E. F. Soares \& A. L. Pinheiro leg., 1 macho (INPA); ibidem, 16.V.2003, arm[adilha] McPhail modificada, $25 \mathrm{~m}$, platô, Tregue-Costa, A. P. leg., 1 fêmea (INPA); E[scola] A[grícola] R[ainha dos] A[póstolos], BR-174, km 23, 28.V.1997, arm[adilha] McPhail, em araticum, B. Ronchi-Teles leg., 1 fêmea (INPA); ibidem, 21.VIII.1997, 2 fêmeas (INPA); ibidem, 23.X.1997, em bacuri, 1 macho (INPA); E[stação] E[xperimental de] F[ruticultura] T[ropical], BR174 km 40, 10.IV.1997, arm[adilha] McPhail, em araçá-boi, B. RonchiTeles leg., 1 fêmea (INPA); ibidem, 10.VII.1997, em araçá-pêra, 1 fêmea (INPA); ibidem, 17.VII.1997, em sorva, 1 fêmea (INPA).

Variações. Grande variação na coloração da face, de branca a preta, com cores intermediárias, como ferrugem e castanhoescuro; coloração da antena também variável, com tons alaranjados, ferrugem ou castanho-escuro; clípeo, palpo e gena seguindo o padrão de coloração da face; gena e pós-gena com cerdas ruivas e/ou pretas. Escuto, às vezes, com 1 faixa acrostical de polinosidade prateada, muito estreita, quase imperceptível; cerda acrostical reduzida em alguns exemplares; catepisterno castanho a castanho-escuro; escutelo com 1 cerda apical, 1 subapical marginal, e 1 discal no $1 / 3$ distal, esta última reduzida; 5-7 cerdas na borda superior do espiráculo metatorácico. Tégula com 4-6 cerdas destacadas. Fêmures inteiramente castanhos; número de cerdas dos fêmures bastante variável, mas com o mesmo padrão de distribuição; tíbias inteiramente castanhas com cerdas pretas; tarsos com coloração variável, amarelada a castanha, os posteriores geralmente mais escuros.

Comentários. Assemelha-se bastante à K. fuliginosa no aspecto geral e coloração, diferindo principalmente pelas seguintes características: tamanho menor; arista com pêlos microscópicos; número menor de cerdas destacadas do escuto; disposição e número das cerdas escutelares, possuindo 1 cerda apical, 1 subapical marginal e 1 discal no terço distal; terminália feminina curta; espermateca arredondada e sem estriações; surstilo pouco esclerotinizado, com 1-3 pequenos dentes somente no ápice e projeção lateral arredondada na base; epifalo curto e engrossado, com ápice arredondado e parâmero com o lóbulo apical externo arredondado e o interno truncado.

Etimologia: do Latim, minor $=$ pequeno (a), refere-se ao menor tamanho dos indivíduos em relação aos de K. fuliginosa.

Agradecimentos. Ao Dr. José Albertino Rafael (INPA), Dr. Orlando Tobias Silveira (MPEG), Dra. Sônia Casari (MZSP), Dra. Ruth Contreras-Lichtenberg/ Dr. Peter Sehnal (NHMW) e Dr. Allen L. Norrbom (USNM) pelo empréstimo dos espécimes, e à Coordenação de Aperfeiçoamento de Pessoal de Nível Superior (CAPES) pela bolsa de mestrado concedida à primeira autora.

\section{REFERÊNCIAS}

AldRICH, J. M. 1932. New Diptera, or two-winged flies from America, Asia, and Java, with additional notes. Proceedings of the United States National Museum 81: 1-28.

Ale-Rocha, R. \& A. P. C. Marques. Ropalomeridae In: C. Magalhães et al. (ed.). A Fauna de Artrópodos da Reserva Florestal Adolpho Ducke. Estado Atual do Conhecimento Taxonômico e Biológico. Manaus, no prelo.

Baez, M. 1985. Los Ropaloméridos de Venezuela (Diptera: Ropalomeridae). Boletín de Entomologia Venezolana 4(10): 77-81.

FISCHER, C. R. 1932. Um gênero e duas espécies novas de Rhopalomeridae do Brasil, e o pupário de Willistoniella pleuropunctata Wied. (Dipt.). Revista de Entomologia 2(4): 441-450.

LindNER, E. 1930. Revision der amerikanischen Dipteren-Familie der Rhopalomeridae. Deutsche Entomologische Zeitschrif 2: 122137.

Malloch, J. R. 1941. Florida Diptera. Family Rhopalomeridae. Florida Entomologist 24(3): 49-51.

McAlpine, J. F. 1981. Morphology and terminology - Adults, p. 9-63. In: J. F. McAlpine (coord.). Manual of Nearctic Diptera. Vol. 1. Res. Branch Agr. Canada Monogr. 27.

Prado, A. P. 1966. Segunda contribuição ao conhecimento da família Rhopalomeridae (Diptera, Acalyptratae). Studia Entomologica 8(1965): 209-268.

Prado, A. P. \& N. Papavero. 2002. Insecta - Diptera - Ropalomeridae, p. 1-3. In: N. Papavero (ed.). Fauna da Amazônia Brasileira. Vol. 5. Belém, Museu Paraense Emílio Goeldi.

RamíreZ-García, E. \& V. HernándeZ-Ortiz. 1994. Revisión de la familia Ropalomeridae (Diptera) en Mexico. Acta Zoologica Mexicana 61: $57-85$

Steyskal, G. C. 1967. Family Ropalomeridae, p. 1-7. In: A catalogue of the Diptera of the Americas South of the United States. São Paulo, Departamento de Zoologia, Secretaria da Agricultura, v. 60.

Steyskal, G. C. 1987. Ropalomeridae, p. 941-944. In: J. F. McAlpine (ed.). Manual of Nearctic Diptera. Vol. 2. Res. Branch Agr. Canada Monogr. 28.

Recebido em 14.X.2003; aceito em 15.VII.2004 